\title{
Dust aerosol effect on semi-arid climate over Northwest China detected from A-Train satellite measurements
}

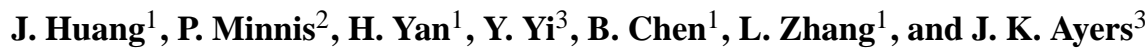 \\ ${ }^{1}$ Key Laboratory for Semi-Arid Climate Change of the Ministry of Education, College of Atmospheric Sciences, \\ Lanzhou University, Lanzhou, 730000, China \\ ${ }^{2}$ NASA Langley Research Center, Hampton, VA, 23666, USA \\ ${ }^{3}$ Science Systems and Applications Incorporated, Hampton, VA, 23666, USA
}

Received: 4 May 2010 - Published in Atmos. Chem. Phys. Discuss.: 12 May 2010

Revised: 16 July 2010 - Accepted: 17 July 2010 - Published: 23 July 2010

\begin{abstract}
The impact of dust aerosols on the semi-arid climate of Northwest China is analyzed by comparing aerosol and cloud properties derived over the China semi-arid region (hereafter, CSR) and the United States semi-arid region (hereafter, USR) using several years of surface and ATrain satellite observations during active dust event seasons. These regions have similar climatic conditions, but aerosol concentrations are greater over the CSR. Because the CSR is close to two major dust source regions (Taklamakan and Gobi deserts), the aerosols over the CSR not only contain local anthropogenic aerosols (agricultural dust, black carbon and other anthropogenic aerosols), but also include natural dust transported from the source regions. The aerosol optical depth, averaged over a 3-month period, derived from MODIS for the CSR is 0.27 , which is $47 \%$ higher than that over the USR (0.19). Although transported natural dust only accounts for $53 \%$ of this difference, it is a major contributor to the average absorbing aerosol index, which is $27 \%$ higher in the CSR (1.07) than in the USR (0.84). During dust event periods, liquid water cloud particle size, optical depth and liquid water path are smaller by $9 \%, 30 \%$ and $33 \%$ compared to dust-free conditions, respectively.
\end{abstract}

\section{Introduction}

Arid and semi-arid areas account for one third of the Earth's surface land area. Semi-arid regions are defined as transition zones between arid and sub humid belts where precipitation is less than the potential evaporation. Semi-arid lands, especially those located in mid-latitude inner continental regions, are some of the most sensitive areas to climate change (Fu et al., 2006; $\mathrm{Ma}$ and $\mathrm{Fu}, 2006$ ). One of these regions is found in western China. During the last few decades, warm winters and dry springs occurred more frequently in northwestern China (Qian et al., 2002; Wang and Zhai, 2004) where, with disturbances brought about by human activity, large areas of vegetation were destroyed, thus giving rise to anthropogenic dust emissions (Mahowald and Luo, 2003; Moulin and Chiapello, 2004; Tegen et al., 2004). Understanding how human activity and the resulting dust emissions affect climate in these semi-arid regions is an essential step for developing mitigation and adaptation strategies to climate changes in these transition areas.

The semi-arid region of northwestern China is close to the Taklamakan and Gobi deserts. Strong winds in those deserts stir large amount of dust into the atmosphere and cause dust events (DS: dust storms, BD: blowing dust and FD: floating dust). Zhang et al. (1997) estimated that about $800 \mathrm{Tg} \mathrm{yr}^{-1}$ of Asian dust emissions are injected into the atmosphere annually, about $30 \%$ of which is re-deposited onto the deserts and $20 \%$ that is transported over regional scales, while the remaining approximately $50 \%$ is subject to long-range transport to the Pacific Ocean and beyond. Strong and extremely strong sandstorms develop as the result of the integrated influences of climate, geography and human factors. Many factors that cause these disasters are natural, but human factors appear to dominate (Liu, 2004). Rising numbers of dust storms are due to increasing desertification, which is fed, in turn, by dust events that exacerbate drought conditions over the semi-arid areas of Northwest China (Han et al., 2008; Wang et al., 2008). 
Dust aerosols not only have direct effects on the climate through reflection and absorption of short- and longwave radiation but also modify cloud properties, such as the number concentration and size of cloud droplets. This change in cloud properties, which can alter both cloud albedo and cloud lifetime (Twomey et al., 1984; Ackerman et al., 2000; Liu et al., 2003; Huang et al., 2006a) if the total cloud water content remains unaffected, constitutes the indirect effect on climate (Penner et al., 1992; Twomey, 1977). Another important aspect of dust aerosols is their semi-direct effect. Dust aerosol absorption at solar wavelengths could contribute to significant diabatic heating in the atmosphere and enhance cloud evaporation (Ackerman et al., 2000; Koren et al., 2004; Huang et al., 2006b). Because clouds are a sustainable water resource for arid and semi-arid regions, small variability or changes in the amount, altitude, physical thickness, and/or microphysical properties of clouds due to natural and human influences can exert changes in the surface radiation budget and hydrological cycle over these regions. Clouds form on aerosol particles, so changes in the amount and/or composition of aerosols can affect clouds in a variety of ways. Thus, the study of aerosol-cloud-radiation-precipitation processes over semi-arid regions is climatically important and possibly more urgently needed for these areas than for any other.

However, knowledge of the interaction between dust aerosols and cloud-precipitation processes is still very limited due to the lack of direct observations. One difficulty in quantifying aerosol effects on clouds is that cloud evolution is profoundly affected not only by aerosols but also by cloud dynamics and thermodynamics. Since aerosol amounts and dynamical factors are often correlated, distinguishing between them requires either special circumstances, e.g., a uniform cloud field that is only perturbed in certain locations by aerosol sources, or statistical analysis of a sufficiently large amount of data in specific cloud dynamic regimes. This study follows both courses. The aerosol-cloud-radiationprecipitation processes are analyzed by comparing cloud properties over semi-arid regions in the United States (US) and China using multiple years of satellite cloud property retrievals and surface observations.

\section{Satellite and surface data}

\subsection{CERES/MODIS data}

Five years (March 2003 to May 2007) of the Clouds and Earth's Radiant Energy System (CERES) Aqua Edition 1B Single Scanner Footprint (SSF; Caldwell et al., 2008) data are used in this study. CERES SSF data sets combine CERES radiation measurements, cloud microphysical property retrievals, and ancillary meteorology fields to form a comprehensive, high-quality compilation of satellite-derived cloud, aerosol, and radiation budget information for radiation and climate studies. There are about 140 parameters in the SSF data set. The current analysis uses four of the SSF parameters, effective droplet radius $\left(R_{\mathrm{e}}\right)$, liquid water path (LWP), cloud optical depth $(\tau)$, and cloud effective height $\left(H_{\mathrm{e}}\right)$, which were derived from 1-km MODerateresolution Imaging Spectroradiometer (MODIS) data using the Visible-Infrared-Solar-infrared-Split-window Technique (VISST) (Minnis et al., 2008, 2010).

\subsection{MODIS aerosol optical depth}

This study uses 5 years (March 2003 to May 2007) of 0.55$\mu \mathrm{m}$ deep-blue aerosol optical depth (AOD) data, which constitute one component of the Aqua MODIS - Aqua Atmosphere Level 2 Joint Products (MYDATML2; Remer et al., 2005). The post-launch MODIS Atmosphere Level 2 Joint Product contains a spectrum of key parameters gleaned from the complete set of standard Level 2 products. The MODIS deep-blue algorithm is especially valuable for this study due to its ability to derive AOD over bright surfaces, such as deserts.

\subsection{OMI absorbing aerosol index}

Two years (March 2005 to May 2007) of the Ozone Monitoring Instrument (OMI) absorbing aerosol index (AAI) are also employed here. The Dutch-Finnish OMI aboard the NASA EOS-Aura satellite is a compact nadir-viewing, wideswath imaging spectrometer that provides daily global coverage with high spatial resolution. OMI measures Earth reflectance spectra both in the visible and the ultraviolet parts of the electromagnetic spectrum $(270-500 \mathrm{~nm})$ at high spectral resolution. This makes OMI especially suited for distinguishing UV-absorbing aerosols, such as desert dust and biomass burning aerosols, from weakly absorbing aerosols and clouds. A convenient observable in this respect is the UV absorbing aerosol index (AAI), which is a measure of the departure of the observed spectrum from that of a hypothetical pure molecular atmosphere. The AAI takes near-zero values for clouds and weakly absorbing aerosols, and positive values for desert dust and biomass burning aerosols (Torres et al., 2007).

\subsection{CALIPSO data}

The Cloud-Aerosol Lidar and Infrared Pathfinder Satellite Observations (CALIPSO) Cloud-Aerosol Lidar with Orthogonal Polarization (CALIOP) instrument acquires vertical profiles of elastic backscatter at two wavelengths (532 and $1064 \mathrm{~nm}$ ) from a near nadir-viewing geometry during both day and night phases of the orbit (Winker et al., 2007). In addition to total backscatter at the two wavelengths, CALIOP also provides profiles of linear depolarization at $532 \mathrm{~nm}$. Dust aerosols can be identified within a given altitude range of a lidar profile based on the volume depolarization ratio, which is defined as the ratio of perpendicular to parallel components of received lidar signals (including both particulate 
and molecular scattering) at $532 \mathrm{~nm}$. The dust depolarization ratio is high due to the nonsphericity of the particles. On the other hand, the depolarization ratio is low (close to zero) for other types of aerosols. Therefore, the depolarization ratio is normally used as an indicator to separate dust from other aerosol types (Murayama et al., 2001).

Based on the first year of CALIPSO measurements (June 2006 to May 2007), Liu et al. (2008) found that dust aerosols, which include DS, BD, FD, and even optically thin dust layers, can be effectively separated from other types of aerosols with a volume depolarization ratio threshold of 0.06 for a 1-km layer average depolarization. This study uses the Liu et al. (2008) dust selection procedure and definition of frequency of dust aerosol occurrence (OCC), i.e.,

$\mathrm{OCC}_{i}=\boldsymbol{N}_{i, \text { dust }} / \boldsymbol{N}_{c f}$

where, $\boldsymbol{N}_{i \text {,dust }}$ and $\boldsymbol{N}_{c f}$ are the number of dusty profiles in the vertical range $(i)$ and the number of cloud-free profiles, respectively, in a $1^{\circ} \times 1^{\circ}$ grid box.

\subsection{NCEP analysis data}

Five years (March 2003 to May 2007) of NCEP FNL (Final) Operational Global Analysis data are also used in this study to eliminate meteorological influences on cloud physical properties. This Global Forecast System (GFS) product is run four times a day at $1.0 \times 1.0$ degree resolution in near-real time at NCEP. Analyses are available on the surface, at 26 mandatory (and other pressure) levels from 1000 to $10 \mathrm{hPa}$, in the surface boundary layer and at some sigma layers, the tropopause and a few others. Parameters include surface pressure, sea level pressure, geopotential height, temperature, sea surface temperature, soil values, ice cover, relative humidity, u- and v-winds, vertical motion, vorticity, and ozone. The thickness of the saturated layer can be derived from humidity profile and geopotential height.

\subsection{Other surface observations}

Surface meteorological data were obtained from the CMA (China Meteorological Administration) and include daily standard surface observations and daily charts. The global temperature and precipitation data used in this study are from CRU TS 2.1, comprising 1224 monthly grids of observed climate factors from the Climatic Research Unit, for the period 1901-2002, and covering the global land surface at a $0.5^{\circ}$ resolution. The climate variable anomaly is calculated by subtracting the annual mean of the period from 1971-2000 from each annual value.

\section{Analysis and results}

Figure 1 shows the global distribution of precipitation, which varies spatially from less than $10 \mathrm{~mm} \mathrm{yr}^{-1}$ to a maximum of more than $1300 \mathrm{~mm} \mathrm{yr}^{-1}$ depending on location. The orange

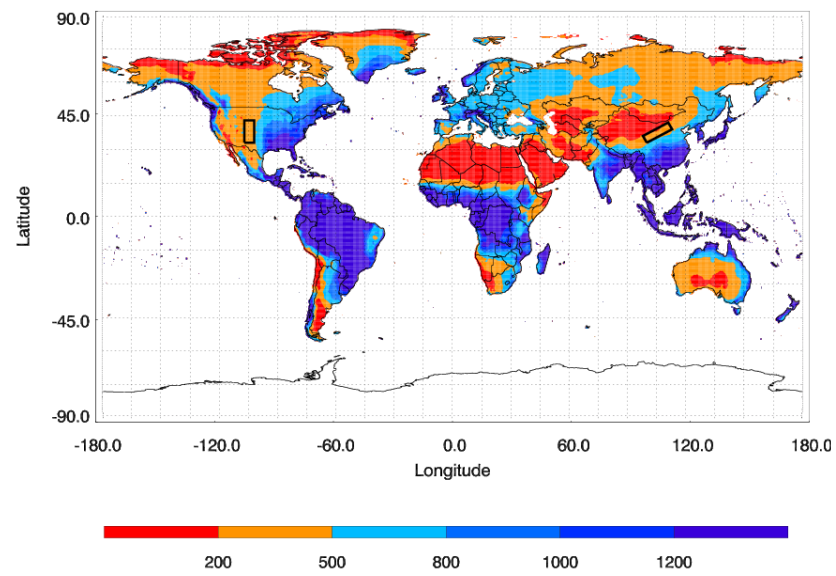

Fig. 1. Global precipitation distribution. The orange color represents the semi-arid regions having annual precipitation ranging from 200 to $500 \mathrm{~mm}$. The black rectangles denote the semi-arid regions over China (CSR) and over the USA (USR) selected for this study.

color represents semi-arid region precipitation ranging from 200 to $500 \mathrm{~mm} \mathrm{yr}^{-1}$. The semi-arid regions are characterized by low and restricted precipitation because moisturebearing winds might not be able to penetrate into and cool down such regions. Semi-arid regions are also defined as areas where precipitation is less than potential evaporation and very high temperatures $\left(30^{\circ}-45^{\circ} \mathrm{C}\right)$ occur often during the hottest months. Both transpiration and evaporation are high in these areas because abundant heat energy is supplied to change the limited amounts of liquid water into water vapor either directly or through biological processes thus maintaining the heat balance of the area. Mid-latitude semi-arid climates cover considerable parts of western North America and central Asia. The type of climate generally has temperature characteristics similar to mid-latitude arid or desert regions. However, mid-latitude semi-arid climates receive slightly more precipitation than mid-latitude arid regions. Semi-arid lands, especially those located in inner continental regions, may be some of the most sensitive to global warming.

To study dust aerosol effects on cloud properties over semi-arid regions, two domains were selected. One is located in the northwestern China and the other is in the western US, denoted as the China semi-arid region (hereafter, CSR) and US semi-arid region (hereafter, USR), respectively. They are indicated by the black rectangles in Fig. 1. These regions have similar climatic environments but clouds in the CSR are contaminated by more dust aerosols than in the USR during active dust event seasons, since the dust aerosols are able to play an important role as cloud condensation nuclear (CCN) (Wang and He, 1989; Fan and An, 2000). The CSR is close to two major dust source regions (Taklamakan and Gobi Deserts), and aerosols over the CSR contain both local anthropogenic aerosols (agriculture dust, industrial black 

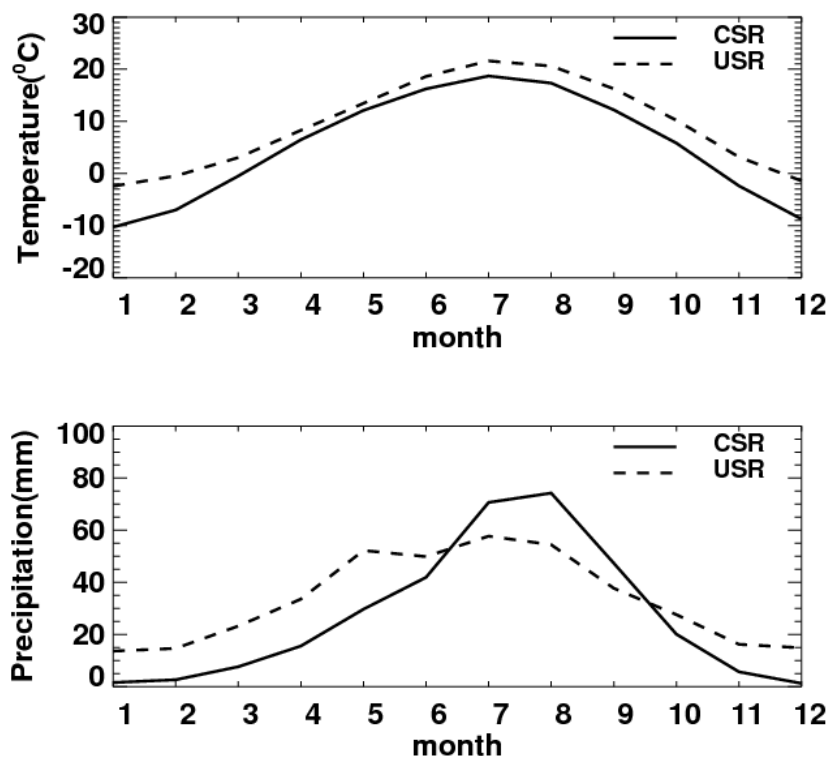

Fig. 2. Comparison of annual temperature $\left({ }^{\circ} \mathrm{C}\right)$ and precipitation (mm) cycles over the CSR and USR.

carbon and other anthropogenic aerosols) and natural dust transported from the source areas.

Figure 2 shows the monthly mean surface temperature and precipitation annual cycles in the two regions. The annual cycle of temperature in both regions is similar with maxima in July and minima in late winter. On average, the USR is warmer by a few degrees. However, the annual cycles of precipitation differ significantly. The CSR precipitation mainly occurs in summer with a maximum in August and is negligible during winter. The precipitation in the USR has a broad maximum during the late spring and the late summer with an average of $\sim 15 \mathrm{~mm}$ during the winter.

Based on dust event records available from the CMA meteorological stations, the seasonal mean frequencies of dust events observed from the surface stations in the CSR are plotted in Fig. 3. The dust events are classified into three categories depending on meteorological conditions: floating-dust (FD), blowing dust (BD) and dust storm (DS) (Wang et al., 2008). In the FD category, dust particles are suspended in the air under calm or low-wind conditions, with horizontal visibility usually less than $10 \mathrm{~km}$. In the BD category, dust and sand particles are physically lifted off the ground by winds, causing horizontal visibility to drop significantly $(<10 \mathrm{~km})$. In the dust storm (DS) category, sand and fine dust particles are frictionally lifted from the ground by strong winds (usually in excess of $5 \mathrm{~m} / \mathrm{s}$ ) under turbid atmospheric conditions. The horizontal visibility is reduced to less than $1 \mathrm{~km}$. In the DS category, mechanically suspended particles can be transported over long distances in the upper atmosphere (Huang et al., 2008). During the peak dust season, spring (MAM), the overall 52-year (1954-2005) total dust event frequency is about $39.3 \%$ in the CSR, about 4 times that during the autum-

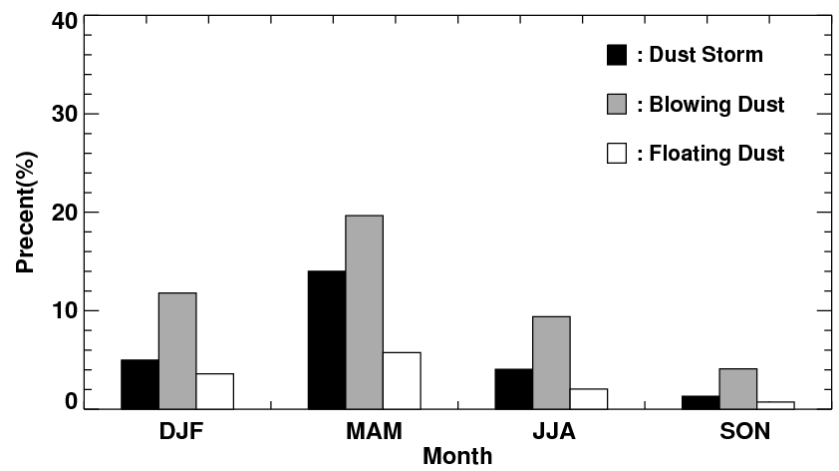

Fig. 3. Dust event category frequency of occurrence for the selected regions. Dust storm (DS) is shown in the black bars, blowing dust (BD) is shown with grey bars, and floating dust (FD) is shown by the white bars.

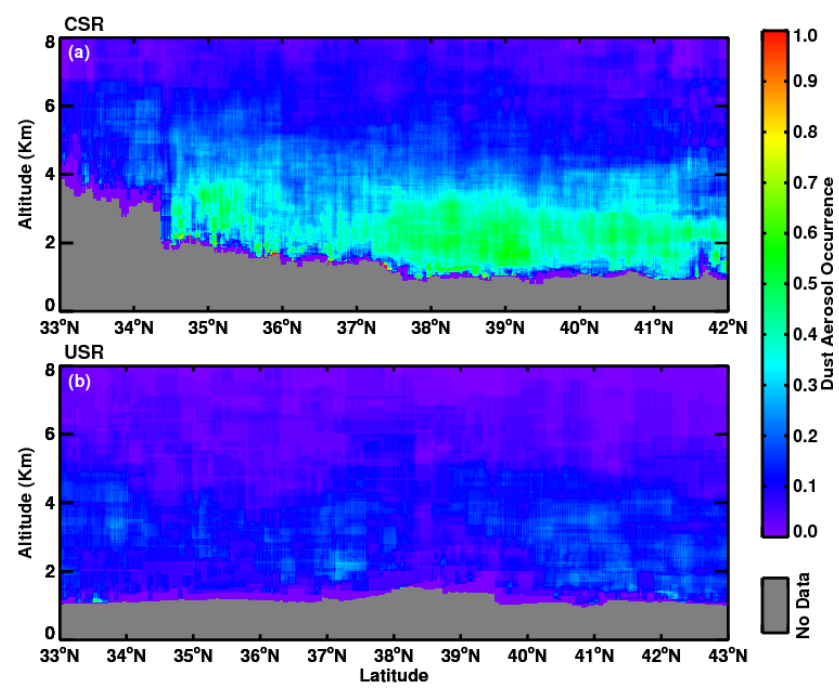

Fig. 4. Vertical structure of dust aerosol occurrence from CALIPSO observations over the (a) CSR and (b) USR in relation to zonal mean regional surface altitude (shown in grey).

nal (SON) minimum. The spring mean BD occurrence frequency is $19.7 \%$ about $5.7 \%$ greater than the mean DS value $(14 \%)$ and $14 \%$ greater than the mean FD value (5.7\%). Because of proximity, dust aerosols from both the Taklamakan and Gobi Deserts are often transported to the CSR by gale and northern cyclone, which are active over the northwestern China. This is the reason that BD occurs more frequently than DS or FD.

Figure 4 compares the CALIPSO-derived vertical structure of dust occurrence over the CSR and USR superimposed on a cross-section of a vertical relief map for each region. It shows much lower dust occurrence over the USR, especially for the northern part of the region. Greater dust occurrence frequency is observed between the surface and $5 \mathrm{~km}$ over the CSR. Between the surface and $2 \mathrm{~km}$ the average occurrence frequency is $38.6 \%$ in the CSR but only $11.1 \%$ in 

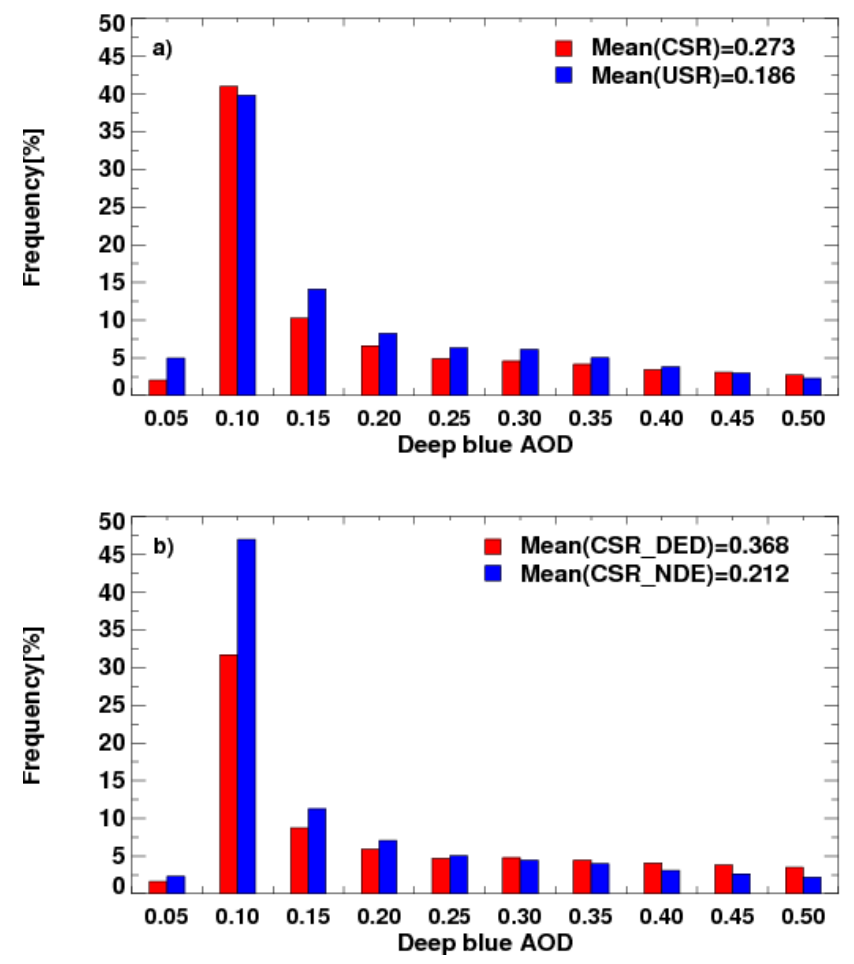

Fig. 5. Comparison of the MODIS deep blue aerosol optical depths (AOD) (a) over the CSR and USR and (b) over the CSR for dust event days (DED) and non dust event days (NDE) during spring (March to May). The histogram intervals are 0.05 .

the USR. The $2-5 \mathrm{~km}$ mean occurrence frequency over the CSR is $27.8 \%$ compared to only $10.8 \%$ over the USR. This difference in dust occurrence is further quantified in Figs. 5 and 6, which compare the MODIS deep-blue aerosol optical depth and OMI Absorbing Aerosol Index, respectively, over the CSR and USR.

To estimate the contribution of transported dust to the aerosol and cloud properties, the daily regional aerosol and cloud properties are averaged according to the dust conditions of each day. If only one surface station in the CSR observed dust storms, blowing dust, or floating dust, those days are defined as dust event days (DED). Otherwise, they are classified as no dust event (NDE) days. Such strict criteria mainly eliminate dust aerosols' effect during NDE days. The mean MODIS deep-blue AOD frequency distributions over the CSR and USR (Fig. 5a) yield a mean AOD of 0.273 over the CSR, which exceeds that over the USR by $47 \%$. Nearly half of the pixels covering the CSR have AOD values larger than 0.20 , while only $40 \%$ of the USR pixels meet this condition. The mean DED AOD (0.368) over the CSR is $74 \%$ higher than for NDE days (Fig. 5b). The mean value of CSR_NDE AOD, highly influenced by agriculture, is also greater than the USR AOD. The CSR_NDE contribution (53\%) to the differences between CSR and USR AOD is greater than the CSR DED
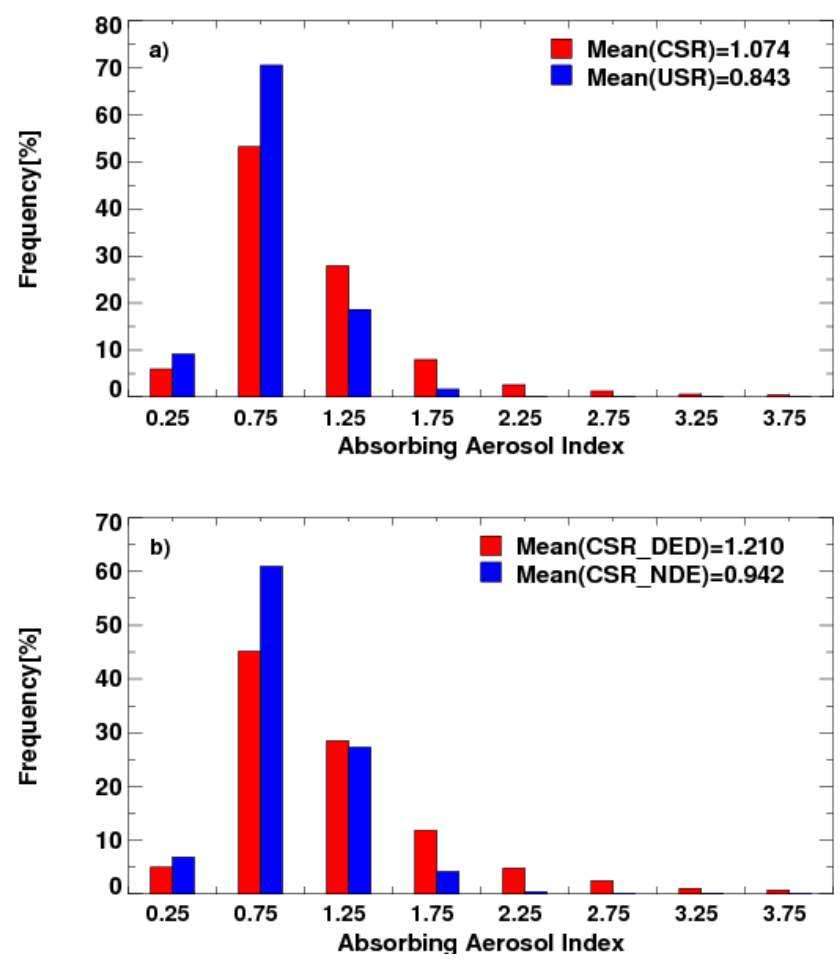

Fig. 6. Same as Fig. 5, but for absorbing aerosol index (AAI). The histogram intervals are 0.5 .

contribution (47\%). Frequency distributions of the OMI absorbing aerosol index (AAI) over the CSR and USR and the CSR AAI dust event days (CSR_DED) and non-dust event days (CSR_NDE) are shown in Fig. 6. These results indicate that the CSR AAI of 1.074 is $27.4 \%$ higher than that over the USR (0.843). Almost $80 \%$ of the USR AAI values are less than 1.0 (Fig. 6a), which is $21 \%$ more than observed for the CSR. Larger ( $>1.0$ ) values of AAI occur more than $41 \%$ of the time for the CSR. During dust event days, the mean CSR AAI is 1.21 (Fig. 6b), which is $29 \%$ higher than that observed during non-dust event days (0.942). This indicates that transported natural dust is a major contributor to solar radiation absorption and heating effects, and should not be ignored. Both the AOD and AAI comparisons suggest that transported natural dust plays an important role in differentiating between the regions, although local aerosols are also quite different between the regions. Huang et al. (2009) found that the single scattering albedo (SSA) of Taklamakan dust aerosols is about 0.89 at $0.67 \mu \mathrm{m}$ which is about $6 \%$ less than for Saharan dust. Ge et al. (2010) also confirmed that the SSA shows an increasing trend with wavelength, indicating stronger dust aerosol absorption at shorter wavelengths. The values of SSA, which range from $0.76 \pm 0.02$ to $0.86 \pm 0.01$, are much lower than those derived in Africa and also relatively smaller than earlier results obtained over East Asia.

Application of the Student t-test to the CSR and USR AOD and AAI reveal significant differences as shown in Table 1. 
Table 1. Summary of Student-T test results for differences in aerosol and cloud properties between the CSR and USR, and CSR_DED and CSR_NDE.

\begin{tabular}{rlrrr}
\hline & & $\begin{array}{r}\text { Mean } \\
\text { Difference }\end{array}$ & $\begin{array}{r}\text { Confidence Interval } \\
\text { of the Difference } \\
\text { Lower }\end{array}$ & Upper \\
\hline \multirow{2}{*}{ AOD } & CSR-USR & 0.08737 & 0.08620 & 0.08855 \\
& DED-NDE & 0.15635 & 0.15444 & 0.15827 \\
\multirow{2}{*}{ AAI } & CSR-USR & 0.23128 & 0.21595 & 0.24661 \\
& DED-NDE & 0.26832 & 0.24797 & 0.28867 \\
\multirow{2}{*}{ Re } & CSR-USR & -1.40577 & -1.55438 & -1.25716 \\
& DED-NDE & -0.95739 & -1.19875 & -0.71604 \\
\multirow{2}{*}{ OPD } & CSR-USR & -1.61631 & -1.96228 & -1.27034 \\
& DED-NDE & -2.59389 & -3.12821 & -2.05957 \\
& CSR-USR & -12.77943 & -14.64299 & -10.91586 \\
& DED-NDE & -15.68786 & -18.44338 & -12.93235 \\
\hline
\end{tabular}
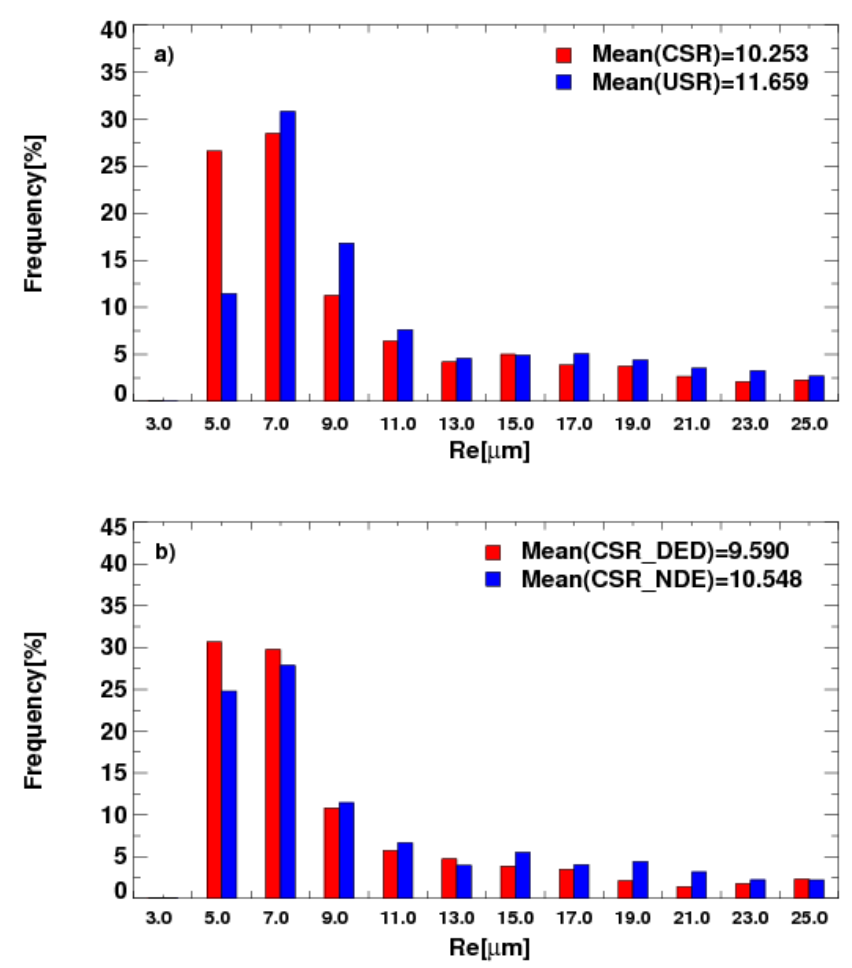

Fig. 7. Same as Fig. 5, except for water cloud radius $\left(R_{\mathrm{e}}\right)$. The histogram intervals are $2 \mu \mathrm{m}$.

The mean differences of AOD and AAI between the CSR and USR are 0.087 and 0.231 , respectively, are within the $95 \%$ confidence intervals of $(0.086,0.089)$ and $(0.216,0.247)$. Thus, the differences between the CSR and USR are statistically significant. Meanwhile, the differences between DED and NDE days are also reliable.
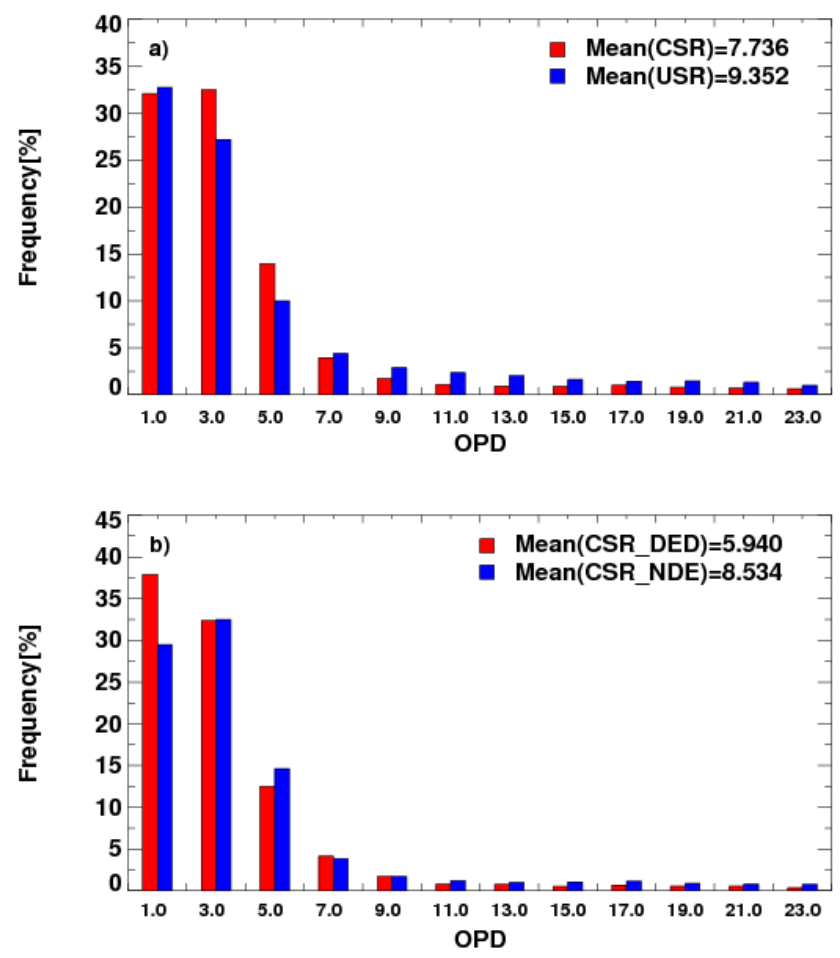

Fig. 8. Same as Fig. 5, but for optical depth (OPD). The histogram intervals are 2 .

Figure 7 examines the variations in effective radius of cloud particles $\left(R_{\mathrm{e}}\right)$ during spring. On average, the CSR mean $R_{\mathrm{e}}$ is $10.3 \mu \mathrm{m}$, which is $12.1 \%$ less than the USR corresponding value (Fig. 7a). Smaller (less than $7 \mu \mathrm{m}$ ) values of $R_{\mathrm{e}}$ occur more frequently in the CSR. As shown in Fig. 7b, the average $R_{\mathrm{e}}$ drops from $10.5 \mu \mathrm{m}$ for an NDE day to $9.6 \mu \mathrm{m}$ for a DED day. Very small values of $R_{\mathrm{e}}\left(2<R_{\mathrm{e}}<8 \mu \mathrm{m}\right)$ occur more frequently for DED than for the NDE days. For a constant liquid water path, dust aerosols might provide extra condensation nuclei thus restraining cloud particle growth and leading to smaller cloud droplets. In comparing Fig. 7a and $\mathrm{b}$, both the mean values of the CSR NDE and DED $R_{\mathrm{e}}$ are less than the overall mean for the USR. Furthermore, the $R_{\mathrm{e}}$ values over the CSR are always smaller than those over the USR for all ranges of fixed LWP. Cloud droplets should be small when an overabundance of particulates is suspended in extremely dry air. In general, this result is consistent with the comparison of AOD over the USR, CSR_DED and CSR_NDE (Fig. 5).

The CSR and USR cloud optical depth (OPD) distributions given in Fig. 8a are similar to the corresponding $R_{\mathrm{e}}$ histograms in Fig. 7a. The mean CSR OPD is less than the USR mean by $17 \%$, and more than $75 \%$ of the CSR OPD values are less than 6.0. The mean OPD for NDE days (Fig. 8b) is 8.5. Furthermore, both the mean CSR OPDs for DED (5.9) and NDE days (8.5) are less than the overall USR mean (9.3). 

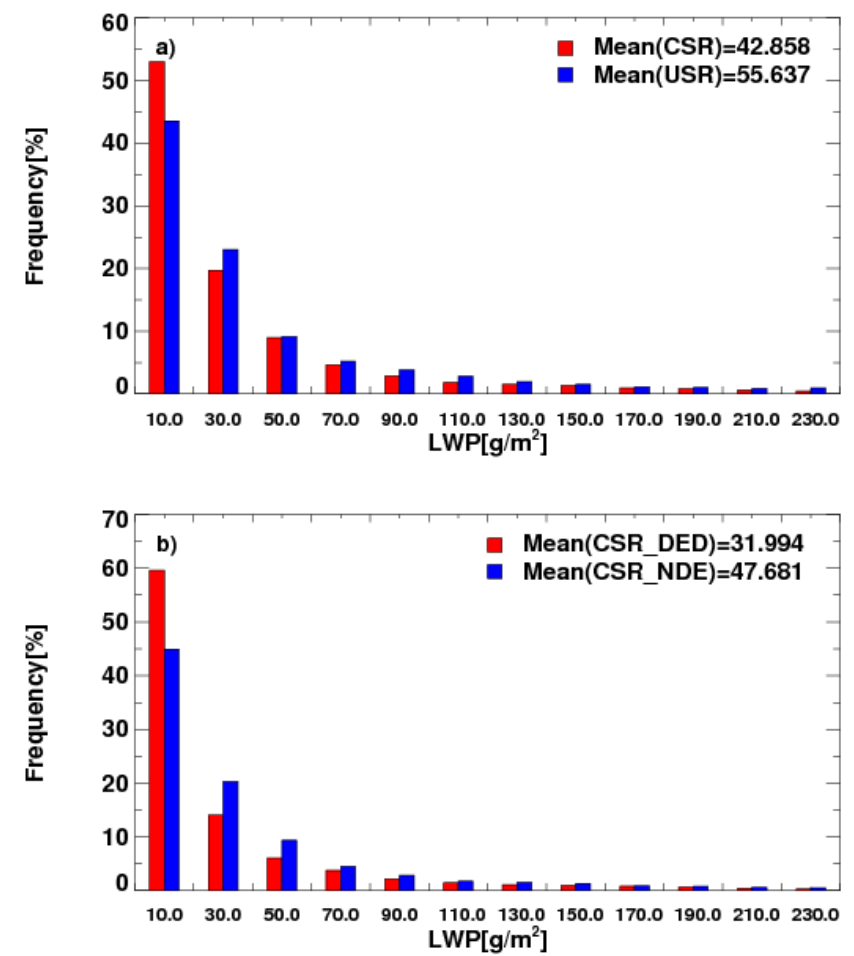

Fig. 9. Same as Fig. 5, but for liquid water path (LWP). The histogram intervals are $20 \mathrm{~g} / \mathrm{m}^{2}$.

Consequently, the mean LWPs of 42.9, 32.0, and $47.7 \mathrm{~g} / \mathrm{m}^{2}$, respectively, for all CSR clouds (Fig. 9a), and for CSR_DED and CSR_NDE clouds (Fig. 9b) are all less than total mean of $55.6 \mathrm{~g} / \mathrm{m}^{2}$ over the USR. More than half of the CSR pixels have LWP $<20 \mathrm{~g} / \mathrm{m}^{2}$. The mean CSR LWP for DED is less than its NDE counterpart by $33 \%$.

Table 1 summarizes the Student t-test results of the previously discussed cloud property differences over the CSR and USR, DED and NDE over the CSR. All of the cloud properties mean differences are significant at the $95 \%$ confidence level. This distinction might be due to the semi-direct effect of abundant absorbing dust aerosols suspended over the CSR, especially during DED days. However, meteorological influences on cloud physical properties have not been completely excluded.

To further estimate the dust aerosol effect on cloud properties alone, Fig. 10 gives the distribution of saturated layer thickness (thickness of contiguous layers having $\mathrm{RH}>85 \%$ ) over the CSR and USR for cloudy days. Although both regions have similar climatic conditions, the thickness of the saturated layer over the CSR $(3721 \mathrm{~m})$ is slightly thicker than that over the USR $(3500 \mathrm{~m})$. Simultaneously, the saturated layer thickness for DED days (3893 m) is also $7.13 \%$ larger than that for NDE days $(3634 \mathrm{~m})$. This leads to the conclusion that the decrease in OPD and LWP over the CSR could be explained by increased droplet evaporation due to the semi-direct effect of dust aerosols in addition to any impacts due to any differences in the average depth of the saturated
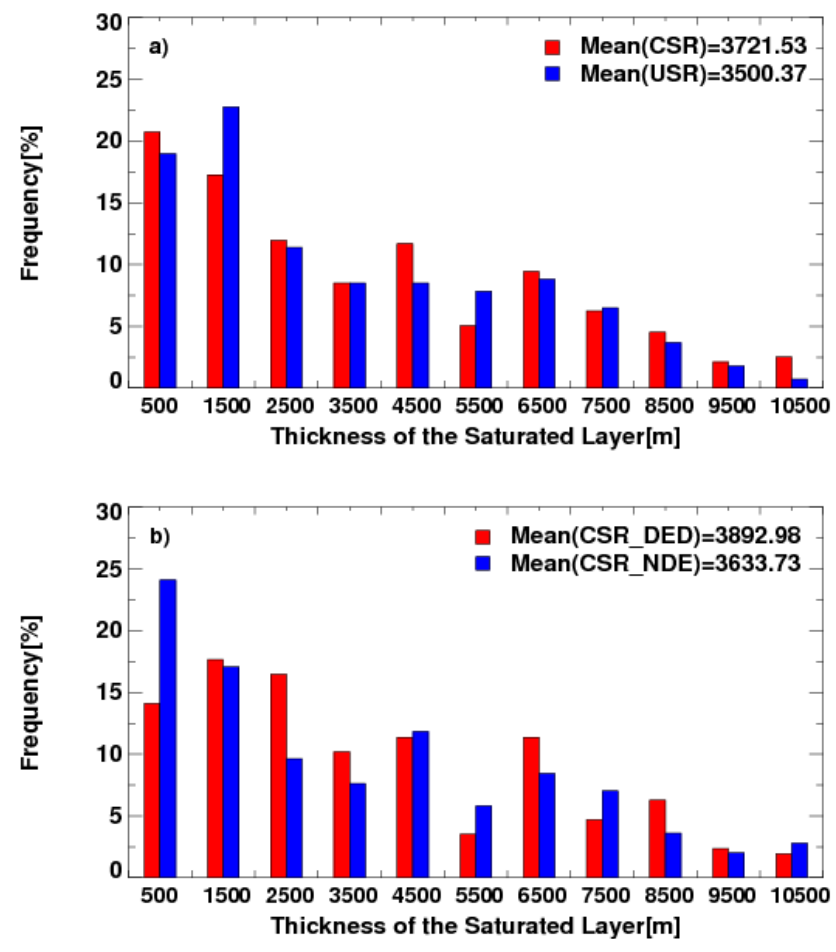

Fig. 10. Same as Fig. 5, but for thickness of cloudy day saturated layer. The histogram intervals are $1000 \mathrm{~m}$.

layers. Even though cloud properties in the CSR are significantly changed by those transported dust aerosols when dust events occur, the local aerosols could also reduce the cloud LWP during NDE days.

To eliminate the influence of meteorological conditions and evaluate the cloud response to aerosol burden, liquid water cloud properties $\left(R_{\mathrm{e}}, \mathrm{OPD}\right.$, and LWP) for the USR, CSR DED, and CSR NDE cases are compared as functions of cloud effective height in Fig. 11. Cloud effective height, calculated by linearly interpolating to cloud effective temperature using profiles of temperature and height, corresponds to some location between the cloud base and top. The CSR NDE mean $R_{\mathrm{e}}$ is slightly less than the USR $R_{\mathrm{e}}$ over most of the range in effective cloud height (Fig. 11a). However, the CSR DED $R_{\mathrm{e}}$ is significantly less than the USR $R_{\mathrm{e}}$, especially for higher-level clouds. For OPD (Fig. 11b) and LWP (Fig. 11c), the averaged binned values decrease with increasing effective cloud height. The observed values of OPD and LWP for the CSR DED and NDE are less than those over the USR over the full range of effective cloud heights. These results are consistent with Fig. 7-9. The $R_{\mathrm{e}}$, OPD and LWP differences between the CSR DED and USR are significant when the cloud effective height exceeds $2 \mathrm{~km}$. This is due to the fact that dust aerosols from both the Taklamakan and Gobi Deserts can be entrained to elevations above $2 \mathrm{~km}$ and transported over long distances by prevailing winds (Huang et al., 2008). 

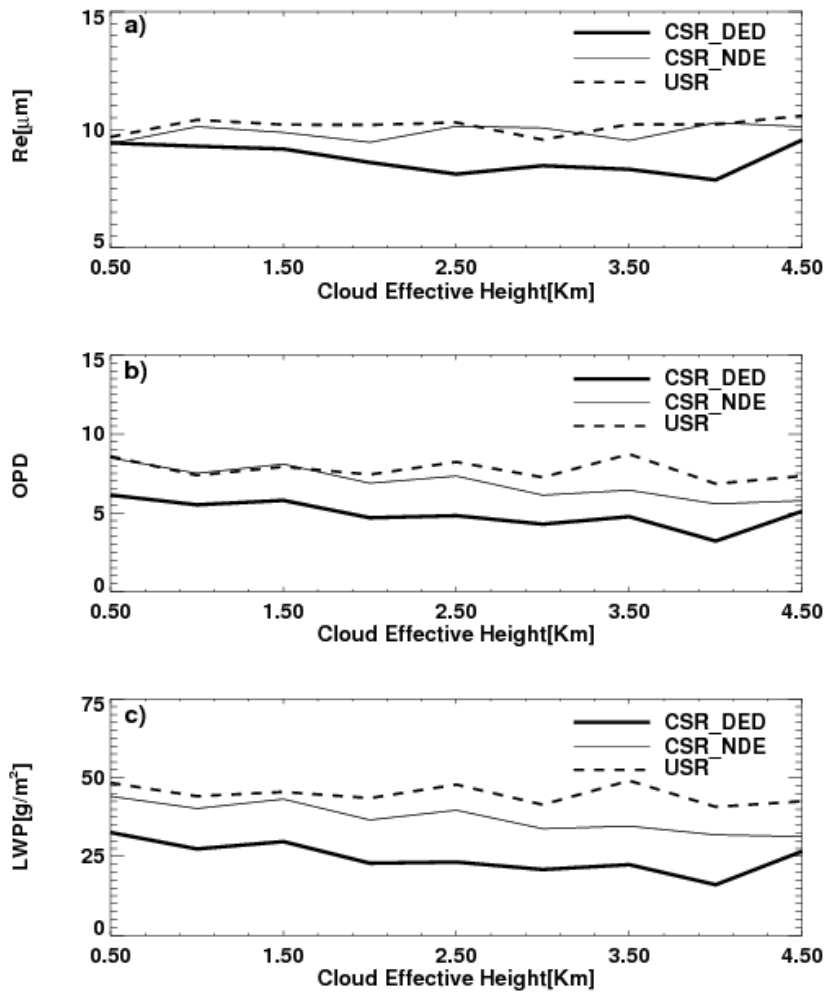

Fig. 11. Comparison of averaged water cloud properties as a function of effective cloud height for (a) $R_{\mathrm{e}}$, (b) OPD, and (c) LWP during spring (March to May).

\section{Discussion and conclusions}

In this study, dust aerosol effects on the semi-arid climate of Northwest China were analyzed by comparing aerosol and cloud properties over the China and US semi-arid regions using multiple years of A-Train satellite-retrieved and surface-observed data during the most active dust event seasons. These regions have similar climatic conditions, but more aerosols are present in the atmosphere over the CSR. Aerosols in the CSR not only contain local anthropogenic aerosols (agricultural dust, industrial black carbon, and other anthropogenic aerosols), but also include dust transported from the nearby Taklamakan and Gobi deserts. The mean spring aerosol optical depth derived from MODIS over the CSR is 0.273 , which is $47 \%$ higher than over the USR. Although transported dust may only contribute $53 \%$ of the difference, it contributes $56 \%$ to the difference in the mean absorbing aerosol index, which is $27.4 \%$ higher for the CSR than for the USR. The local anthropogenic dust aerosol due to human activity, such as agriculture and industrial activity, accounts for $44 \%$ of the average absorbing aerosol index and for $77 \%$ of the cloud liquid water path difference between the CSR and USR regions. This suggests that the local anthropogenic absorbing aerosols also make some contribution to the regional interaction among aerosol-cloud-radiation- precipitation processes and need to be further investigated. Tegen and Fung (1995) estimated the anthropogenic contribution of mineral dust to be 30 to $50 \%$ of the total dust burden in the atmosphere. Tegen et al. (2004) provided an updated, alternative estimate by comparing observations of visibility, as a proxy for dust events, from over 2000 surface stations with model results, and suggested that only 5 to $7 \%$ of mineral dust comes from anthropogenic agricultural sources.

Although the potential importance of the semi-direct effect has been addressed by model simulations, there are few reports discussing the semi-direct effect as seen from observational data. This study shows some evidence of the semi-direct effect of Asian dust aerosols on cloud properties. Analysis of satellite observations indicates that, on average, both natural transported and local anthropogenic dust aerosols can significantly reduce the water cloud particle size, optical depth and liquid water path. These results suggest that dust aerosols warm the clouds and increase evaporation of cloud droplets, further reducing cloud water path, i.e., the so-called semi-direct effect. Such semi-direct effects may play an important role in cloud development and act to exacerbate drought conditions over semi-arid areas of Northwest China (Huang et al., 2006a, b). The semi-direct effect has been simulated with GCMs and high-resolution cloud-resolving models, since it is implicitly taken into account whenever absorbing aerosols coupled to the radiation scheme are included (Hansen et al., 1997; Lohmann and Feichter, 2001; Jacobson, 2002; Menon et al., 2002; Penner et al., 2003; Cook and Highwood, 2004; Hansen et al., 2005). Aerosol heating within cloud layers reduces cloud fraction, whereas aerosol heating above the cloud layer tends to increase cloud fraction. When diagnosed within a GCM framework, the semi-direct effect can also include cloud changes due to circulation effects and/or surface albedo effects. Moreover, the semi-direct effect is not exclusive to absorbing aerosols, as cumulus and stratocumulus case studies have also diagnosed semi-direct effects indicating a similar relationship between the height of the aerosol layer relative to the cloud and the sign of the semi-direct effect (Ackerman et al., 2000; Ramanathan et al., 2001; Johnson et al., 2004; Johnson, 2005).

Based on measurements at Mt. Hua near Xi' an, in central China, Rosenfeld et al. (2007) found that precipitation over hilly regions can be decreased by 30-50\% during hazy conditions, when visibility is less than $8 \mathrm{~km}$ at the mountaintop. This trend shows the role of air pollution in the loss of significant water resources in hilly areas, which is a major problem in China and many other areas of the world. Dai et al. (2008) found that precipitation less than $30 \mathrm{~mm}$ and $5 \mathrm{~mm}$, respectively, can be affected by the aerosols entering the clouds near the Mt. Hua and Xi' an stations, suggesting that as more aerosols enter the clouds, the precipitation will be suppressed in the deeper clouds. Using a two-dimensional spectral resolving cloud model, the effects of mineral dust particles on the development of cloud microphysical and (precipitation) 
were simulated in North China (Yin and Chen, 2007). The results showed that when dust particles are involved in cloud development as CCN (cloud condensation nuclei) and IN (ice nuclei) at the same time, the increased dust aerosols will suppress the precipitation because the enhancing effect of GCCN is almost suppressed by the stronger suppressing effect of IN (Yin and Chen, 2007).

The contributions to the cloud radiation forcing by the dust direct, indirect and semi-direct effects have been estimated using combined satellite observations in radiative transfer model simulation by Jing Su et al. (2008). They found that the 4-year mean value of the combined indirect and semi-direct shortwave radiative forcing is $82.2 \mathrm{Wm}^{-2}$, which is $78.4 \%$ of the total dust effect. The direct effect is only $22.7 \mathrm{Wm}^{-2}$, which is $21.6 \%$ of the total effect. Because both first and second indirect effects enhance cloud cooling, the aerosol-induced cloud warming is mainly the result of the semi-direct effect of dust.

The results presented in this paper are based on satellite observations and further confirm the semi-direct effect of Asian dust, which includes not only transported natural dust, but also local anthropogenic aerosols. Further research should be undertaken to demonstrate the effect of Asian dust based on surface measurements and to give a more complete understanding of aerosol-cloud-radiation-precipitation processes.

Acknowledgements. This research is supported by National Science Foundation of China under grant (40725015, and 40633017) and by the NASA Science Mission through the CALIPSO Project and the Radiation Sciences Program. The CERES SSF and CALIPSO data were obtained from the NASA Earth Observing System Data and Information System, Langley Research Center Atmospheric Sciences Data Center (ASDC). The MODIS AOD and OMI AAI data were obtained from the NASA Earth Observing System Data and Information System, Distributed Active Archive Center (DAAC) at the Goddard Earth Sciences (GES) Data and Information Services Center (DISC).

Edited by: Q. Fu

\section{References}

Ackerman, A. S., Toon, O. B., Stevens, D. E., Heymsfield, A. J., Ramanathan, V., and Welton, E. J.: Reduction of tropical cloudiness by soot, Science, 288, 1042-1047, doi:10.1126/science.288.5468.1042, 2000.

Caldwell, T. E., Coleman, L. H., Cooper, D. L., Escuadra, J., Fan, A., Franklin, C. B., Halvorson, J. A., Hess, P. C., Kizer, E. A., McKoy, N. C., Murray, T. D., Nguyen, L. T., Nolan, S. K., Raju, R. J., Robbins, L., Stassi, J. C., Sun-Mack, S., Tolson, C. J., Costulis, P. K., Geier, E. B., Kibler, J. F., and Mitchum, M. V.: Clouds and the Earth's Radiant Energy System (CERES) Data Management System Data Products Cata$\log$, Release 4 Version 16, 240 pp., online available at: http: //eosweb.larc.nasa.gov/PRODOCS/ceres/DPC/, February, 2008.
Cook, J. and Highwood, E. J.: Climate response to tropospheric absorbing aerosols in an intermediate general circulation model, Q. J. Roy. Meteor. Soc., 130, 175-191, 2004.

Dai, J., Yu, X., Rosenfeld, D., and Xu, X.: The suppression of aerosols to the orographic precipitation in the Qinling Mountains, Chinese J. Atmos. Sci., 32, 1319-1332, 2008 (in Chinese).

Fan, S. X. and An, X. L.: Measurement and analysis of the concentration of cloud condensation nuclei in MT. Helanshan area, Journal of Desert Research, 20, 338-340, 2000.

Fu, Q., Johanson, C. M., Wallace, J. M., and Reichler, T.: Enhanced mid-latitude tropospheric warming in satellite measurements, Science, 312, 1179, doi:10.1126/science.1125566, 2006.

Ge, J. M., Su, J., Ackerman, T. P., Fu, Q., Huang, J. P., and Shi, J. S.: Dust Aerosol Optical Properties Retrieval and Radiative Forcing over Northwestern China during the 2008 China-US Joint Field Experiment, J. Geophys. Res., doi:10.1029/2009JD013263, in press, 2010.

Han, Y., Dai, X., Fang, X., Chen, Y., and Kang, F.: Dust aerosols: A possible accelerant for an increasingly arid climate in North China, J. Arid Environ., 72, 1476-1489, doi:10.1016/j.jaridenv.2008.02.017, 2008.

Hansen, J. E., Sato, M., and Ruedy, R.: Radiative forcing and climate response, J. Geophys. Res, 102, 6831-6864, 1997.

Hansen, J., Sato, M., Ruedy, R., Nazarenko, L., Lacis, A., Schmidt, G. A., Russell, G., Aleinov, I., Bauer, M., Bauer, S., Bell, N., Cairns, B., Canuto, V., Chandler, M., Cheng, Y., Genio, A. D., Faluvegi, G., Fleming, E., Friend, A., Hall, T., Jackman, C., Kelley, M., Kiang, N., Koch, D., Lean, J., Lerner, J., Lo, K., Menon, S., Miller, R., Minnis, P., Novakov, T., Oinas, V., Perlwitz, Ja., Perlwitz, Ju., Rind, D., Romanou, A., Shindell, D., Stone, P., Sun, S., Tausnev, N., Thresher, D., Wielicki, B., Wong, T., Yao, M., and Zhang, S.: Efficacy of climate forcings, J. Geophys. Res., 110(D18), D18104, doi:10.1029/2005JD005776, 2005.

Huang, J., Minnis, P., Lin, B., Wang, T., Yi, Y., Hu, Y., SunMack, S., and Ayers, K.: Possible influences of Asian dust aerosols on cloud properties and radiative forcing observed from MODIS and CERES, Geophys. Res. Lett., 33, L06824, doi:10.1029/2005GL024724, 2006a.

Huang, J., Lin, B., Minnis, P., Wang, T., Wang, X., Hu, Y., Yi, Y., and Ayers, J. R.: Satellite-based assessment of possible dust aerosols semi-direct effect on cloud water path over East Asia, Geophys. Res. Lett., 33, L19802, doi:10.1029/2006GL026561, 2006 b.

Huang, J., Minnis, P., Chen, B., Huang, Z., Liu, Z., Zhao, Q., Yi, Y., and Ayers, J. K.: Long-range transport and vertical structure of Asian dust from CALIPSO and surface measurements during PACDEX, J. Geophys. Res., 113, D23212, doi:10.1029/2008JD010620, 2008.

Huang, J., Fu, Q., Su, J., Tang, Q., Minnis, P., Hu, Y., Yi, Y., and Zhao, Q.: Taklimakan dust aerosol radiative heating derived from CALIPSO observations using the Fu-Liou radiation model with CERES constraints, Atmos. Chem. Phys., 9, 4011-4021, doi:10.5194/acp-9-4011-2009, 2009.

Jacobson, M. Z.: Control of fossil-fuel particulate black carbon and organic matter, possibly the most effective method of slowing global warming, J. Geophys. Res, 107(D19), 4410, doi:10.1029/2001JD001376, 2002.

Jing Su, Jianping Huang, Qiang Fu, Minnis, P., Jinming Ge, and Jianrong Bi: Estimation of Asian dust aerosol effect on 
cloud radiation forcing using $\mathrm{Fu}$-Liou radiative model and CERES measurements, Atmos. Chem. Phys., 8, 2763-2771, doi:10.5194/acp-8-2763-2008, 2008.

Johnson, B. T., Shine, K. P., and Forster, P. M.: The semi-direct aerosol effect: Impact of absorbing aerosols on marine stratocumulus, Q. J. Roy. Meteor. Soc., 130, 1407-1422, 2004.

Johnson, B. T.: The semidirect aerosol effect: Comparison of a single-columm model with large eddy simulation for marine stratocumulus, J. Climate, 18, 119-130, 2005.

Koren I., Kaufman, Y. J., Remer, L. A., and Martins, J. V.: Measurement of the effect of Amazon smoke on inhibition of cloud formation, Science, 303, 1342-1345, 2004.

Liu, G., Shao, H., Coakley Jr., J. A., Curry, J. A., Haggerty, J. A., and Tschudi, M. A.: Retrieval of cloud droplet size from visible and microwave radiometric measurements during INDOEX: Implication to aerosols indirect radiative effect, J. Geophys. Res., 108(D1), 4006, doi:10.1029/2001JD001395, 2003.

Liu, S.: Sand-dust storm, population and environment in northwest China, Chinese Journal of Population Resources and Environment, 2(4), 17-24, 2004.

Liu, Z., Liu, D., Huang, J., Vaughan, M., Uno, I., Sugimoto, N., Kittaka, C., Trepte, C., Wang, Z., Hostetler, C., and Winker, D.: Airborne dust distributions over the Tibetan Plateau and surrounding areas derived from the first year of CALIPSO lidar observations, Atmos. Chem. Phys., 8, 5045-5060, doi:10.5194/acp-85045-2008, 2008.

Lohmann, U. and Feichter, J.: Can the direct and semi-direct aerosol effect compete with the indirect effect on a global scale?, Geophys. Res. Lett., 28(1), 159-161, doi:10.1029/2000GL012051, 2001.

Ma, Z. and Fu, C.: Some evidences of drying trend over North China from 1951 to 2004, Chinese Sci. Bull., 51(23), 2913-2925, 2006 (in Chinese).

Mahowald, N. M. and Luo, C.: A less dusty future? Geophys. Res. Lett., 30(7), 1903, doi:10.1029/2003GL017880, 2003.

Menon, S., Hansen, J., Nazarenko, L., and Luo, Y.: Climate effects of black carbon aerosols in China and India, Science, 297, 22502252, 2002.

Minnis, P., Trepte, Q. Z., Sun-Mack, S., Chen, Y., Doelling, D. R., Young, D. F., Spangenberg, D. A., Miller, W. F., Wielicki, B. A., Brown, R. R., Gibson, S. C., and Geier, E. B.: Cloud detection in non-polar regions for CERES using TRMM VIRS and Terra and Aqua MODIS data, IEEE Trans. Geosci. Remote Sens., 46, 3857-3884, 2008.

Minnis, P., Sun-Mack, S., Young, D. F., Heck, P. W., Garber, D. P., Chen, Y., Spangenberg, D. A., Arduini, R. F., Trepte, Q. Z., Smith Jr., W. L., Ayers, J. K., Gibson, S. C., Miller, W. F., Chakrapani, V., Takano, Y., Liou, K.-N., and Xie, Y.: CERES Edition-2 cloud property retrievals using TRMM VIRS and Terra and Aqua MODIS data, Part I: Algorithms, IEEE Trans. Geosci. Remote Sens., in review, 2010

Moulin, C. and Chiapello, I.: Evidence of the control of summer atmospheric transport of African dust over the Atlantic by Sahel sources from TOMS satellites (1979-2000), Geophys. Res. Lett., 31, L02107, doi:10.1029/2003GL018931, 2004.

Murayama, T., Sugimoto, N., Uno, I., Kinoshita, K., Aoki, K., Hagiwara, N., Liu, Z., Matsui, I., Sakai, T., Shibata, T., Arao, K., Sohn, Byung-Ju, Won, Jae-Gwang, Yoon, Soon-Chang, Li, T., Zhou, J., Hu, H., Abo, M., Iokibe, K., Koga, R., and Iwasaka,
Y.: Ground-based network observation of Asian dust events of April 1998 in east Asia, J. Geophys. Res., 106(D16), 1834518360, 2001.

Penner, J. E., Dickinson, R. E., and O'Neill, C. A.: Effects of aerosol from biomass burning on the global radiation budget, Science, 256, 1432-1434, 1992.

Penner, J. E., Zhang, S. Y., and Chuang, C. C.: Soot and smoke aerosol may not warm climate, J. Geophys. Res., 108(21), 4657, doi:10.1029/2003JD003409, 2003.

Qian, W. H., Quan, L. S., and Shi, S. Y.: Variations of the dust storm in China and its climatic control, J. Climate, 15, 12161229, 2002.

Ramanathan, V., Crutzen, P. J., Kiehl, J. T., and Rosenfeld, D.: Aerosols, climate, and the hydrological cycle, Science, 294, 2119-2123, 2001.

Remer, L. A., Kaufman, Y. J., Tanré, D., Mattoo, S., Chu, D. A., Martins, J. V., Li, R. R., Ichoku, C., Levy, R. C., Kleidman, R. G., Eck, T. F., Vermote, E., and Holben, B. N.: The MODIS Aerosol Algorithm, Products, and Validation, J. Atmos. Sci., 62, 947-973, 2005.

Rosenfeld, D., Dai, J., Yu, X., Yang, X., and Du, C.: Inverse relations between amounts of air pollution and orographic precipitation, Science, 315 ,1396-1398, 2007.

Tegen, I. and Fung, I.: Contribution to the atmospheric mineral aerosol load from land surface modification, J. Geophys. Res., 100, 18707-18726, 1995.

Tegen, I., Werner, M., Harrison, S. P., and Kohfeld, K. E.: Relative importance of climate and land use in determining present and future global soil dust emission, Geophys. Res. Lett., 31, L05105, doi:10.1029/2003GL019216, 2004.

Torres, O., Tanskanen, A., Veihelmann, B., Braak, R., Veefkind, J. P., Levelt, P. F., Barthia, P. K., Ahn, C., and Seftor, C.: Aerosols and Surface UV Products from OMI Observations: An Overview, J. Geophys. Res., 112, D24S47, doi:10.1029/2007JD008809, 2007.

Twomey, S.: The influence of pollution on the shortwave albedo of clouds, J. Atmos. Sci., 34, 1149-1152, 1977.

Twomey, S., Piepgrass, M., and Wolfe, T. L.: An assessment of the impact of pollution on global cloud albedo, Tellus B, 36, 356366, 1984.

Wang, P. Y. and He, S. Q.: CCN concentration in troposphere over China, Adv. Atmos. Sci., 6, 424-433, 1989.

Wang, X., Huang, J., Ji, M., and Higuchi, K.: Variability of East Asia dust events and their long-term trend, Atmos. Environ., 4, 3156-3165, 2008.

Wang, X. L. and Zhai, P. M.: Variation of spring dust storms in China and its association with surface winds and sea level pressures, Acta Meteorol. Sin., 62, 96-103, 2004 (in Chinese).

Winker D., Hunt, W., and McGill, M.: Initial Performance Assessment of CALIOP, Geophys. Res. Lett., 34, L19803, doi:10.1029/2007GL030135, 2007.

Yin, Y. and Chen, L.: The effects of heating by transported dust layers on cloud and precipitation: a numerical study, Atmos. Chem. Phys., 7, 3497-3505, doi:10.5194/acp-7-3497-2007, 2007.

Zhang, X. Y., Arimoto, R., and An, Z. S.: Dust emission from Chinese desert sources linked to variations in atmospheric circulation, J. Geophys.Res., 102, 28041-28047, 1997. 